\title{
Os mortos do século $X X:$ o passado em fragmentos e pequenas histórias
}

\author{
Dilma Beatriz Rocha Juliano*
}

\begin{abstract}
Resumo
Comprometido com o sentido político das narrativas sobre a história, este artigo aproxima Marcelo Masagão a Walter Benjamin, desejando uma leitura interpretativa do 'filme-ensaio' Nós que aqui estamos por vós esperamos (1998). Longe de pretender legendar a narrativa imagética de Masagão com os conceitos de Benjamin, a reflexão aqui proposta reafirma a tarefa de revirar os escombros do passado para pensar o presente. Considerando uma das obras cinematográficas brasileiras mais instigantes para pensar o papel político dos espectadores como cidadãos, discute-se o 'filmeensaio' na perspectiva da experiência artística como forma de conhecimento.
\end{abstract}

\section{Palavras-chave}

Filme-ensaio. História cultural. Marcelo Masagão. Walter Benjamin.

Cultura é o conjunto das obras humanas que expressam uma civilização, significando a relação que os humanos, socialmente organizados, estabelecem com o tempo e com o espaço, com os outros humanos e com a natureza; relações que se transformam e variam em condições temporais e sociais determinadas. A partir destas indicações que veem, aqui sintetizadas, de Marilena Chauí (2006) já é possível localizar Nós que aqui estamos, por vós esperamos num movimento de desnaturalização da história do "ocidente", no século XX. O que o filme reúne são imagens das relações políticas estabelecidas, no século que passou, sob as condições da história cultural que denominados modernidade.

Filme dirigido por Marcelo Masagão, exibido em 1998, premiado em diversos festivais, é classificado por alguns como documentário - por assemelhar-se a um registro histórico -, e por outros denominado vídeo-poema - dada à sensibilidade, criatividade e potência estética contidas nas imagens. No entanto, Arlindo Machado (2003) trabalha o conceito de 'filme-ensaio' que parece melhor inserir Nós que aqui estamos... na historiografia cinematográfica brasileira, aproximando-o da classificação

\footnotetext{
* Doutora em Teoria Literária. Professora da Universidade do Sul de Santa Catarina - UNISUL.
} 
mais recorrente, e desconfortável, deste filme como documentário. Para Machado (2003, p. 63) 'filme-ensaio' são "ensaios em forma de enunciados audiovisuais". E, apoiando-se em Adorno', refere-se à forma ensaística,

denominamos uma certa modalidade de discurso científico ou filosófico que carrega atributos amiúde considerados 'literários', como a subjetividade do enfoque [...], a eloqüência da linguagem [...] e a liberdade de pensamento [...], em vez da simples comunicação de idéias. (MACHADO, 2003, p. 63)

Em Nós que aqui estamos... o tema está na história da modernidade, do século passado, guardada nas imagens produzidas nesse tempo/espaço. As imagens arquivadas documentam o desenrolar dos fatos/atos políticos e culturais do ocidente; daí o arquivo ser a fonte. Mas não como usualmente se pensa a produção documental, aquelas captadas imediatamente do mundo "real", são arquivos trabalhados criativamente. Os arquivos, nas mãos de Masagão, equiparam-se ao conceito enunciado por Arlindo Machado (2003, p. 72),

Ele [filme-ensaio] pode ser construído com qualquer tipo de imagem-fonte: imagens captadas por câmeras, desenhadas ou geradas por computador, além de textos obtidos em geradores de caracteres, gráficos e também materiais sonoros de toda espécie. É por isso que o filme-ensaio ultrapassa longinquamente os limites do documentário. Ele pode inclusive utilizar cenas ficcionais, tomadas em estúdio com atores, porque a sua verdade não depende de nenhum 'registro' imaculado do real, mas de um processo de busca e indagação conceitual.

Com 90 \% de imagens de arquivos, extratos de documentários e de obras clássicas do cinema de ficção, o filme espalha uma sonorização composta e arranjada por Win Mertens e André Abujamra, que intercalam música, silêncio e canto lírico, que ao mesmo tempo ressaltam e lamentam os fatos ali mostrados. Fred Astaire dança, sapateia e Garrincha dribla, chuta, ambos colocados em imagens intercaladas, mostrando seus pés prodigiosos embalados pela mesma música - equivalência da forma espetacular de entretenimento das massas: futebol brasileiro e musical hollywoodiano.

A marca ensaística em Masagão aparece explicitamente na forma cambiante e dinâmica do discurso que implica tanto o sujeito que mostra quanto aquele que vê. Ao desnaturalizar o discurso desenvolvimentista da modernidade, ele assume a liberdade da criação de um outro discurso sobre o universo de idéias, personagens e fatos que compuseram um século. E ainda, usando os recursos tecnológicos, explora as possibilidades do DVD (como suporte de registro e divulgação), expandindo aos

\footnotetext{
${ }^{1}$ No texto intitulado O ensaio como forma, no qual se baseia Arlindo Machado (2003) para definir a forma ensaística, Theodor Adorno (2003, p. 25) afirma, "O ensaio não segue as regras do jogo da ciência e da teoria organizadas, segundo as quais, diz a formulação de Spinoza, a ordem das coisas seria o mesmo que a ordem das idéias. Como a ordem dos conceitos, uma ordem sem lacunas, não equivale ao que existe, o ensaio não almeja uma construção fechada, dedutiva ou indutiva. Ele se revolta sobretudo contra a doutrina, arraigada desde Platão, segundo a qual o mutável e o efêmero não seriam dignos da filosofia."
} 
espectadores a liberdade de assistir às imagens na sequência que escolher - além de romper com a linearidade da história oficialmente contada, o espectador autodetermina a ordem de assistir, aproximando os fragmentos. ${ }^{2}$

Marcelo Masagão e Nicolau Sevcenko assinam o roteiro deste filme, o primeiro, um cineasta crítico de seu tempo, autor de outros filmes de longa e curta metragens com igual teor de comprometimento político no fazer arte; o segundo, um professor, historiador da cultura, crítico literário e estudioso da modernidade. Ambos apoiados em grandes pensadores da cultura, da política, da filosofia e das artes que foram Walter Benjamin, Sigmund Freud e Eric Hobsbaw armam uma trama narrativa que, abolindo a linearidade dos discursos da história, apresentam as imagens na medida da fragmentação com que os fatos efetivamente se desenrolaram em diferentes espaços do chamado lado ocidental do planeta.

Masagão, ao longo dos aproximadamente 72 minutos, explode a história oficialmente contada como uma sucessão natural de fatos - "A" História do século XX - e mostra as pequenas histórias encobertas nos grandes eventos que costumam representar a humanidade em sua trajetória de "desenvolvimento". A contundência das imagens dispostas num mosaico não deixa dúvidas sobre as relações políticas entre os eventos, principalmente por não serem mostradas sob a convenção causaefeito.

Muitas são as sensibilidades despertadas pelas imagens: a dor das guerras, o horror das mutilações, o encantamento com a tecnologia, a identificação com as origens opressoras do trabalho, a vergonha da imobilidade - enfim, o enfrentamento com o humano, "demasiadamente humano" do século que passou, "[...] imagens do passado, que a história transforma em coisa sua" (BENJAMIN, 1994, p. 223).

Partindo de uma frase encontrada na entrada/saída de um pequeno cemitério de cidade do interior do Brasil que dá título ao filme-ensaio, Masagão alia um conhecimento circulante na academia e nos meios intelectuais à sensibilidade do olhar cinematográfico, criando um "complexo mosaico de memórias do século $X X$ " (Sevcenko, 2008). O ponto de partida revela o percurso, o filme parte do mínimo, do prosaico, daquilo que escapa "aos grandes olhares", às "grandes produções", ao que foi considerado relevante e representativo da grande história da humanidade. Nas palavras de Benjamin (1994, p. 223), "O cronista que narra os acontecimentos, sem distinguir entre os grandes e os pequenos, leva em conta a verdade de que nada do que um dia aconteceu pode ser considerado perdido para a história". Sobre a guerra, por exemplo, o filme mostra o casamento do soldado, a separação da noiva para o embarque e, realça, a participação de cada um no sacrifício - ela trabalhando na fabricação da munição das armas que ele dispara no front da guerra.

Os autores desvelam, descobrem, espanam a poeira, "lêem a história a contrapelo", tal qual Benjamin afirmava ser necessário à tarefa de todo pensador do

${ }^{2}$ A primeira versão do filme foi lançada em VHS, o que limitou a sequência de imagens à edição da fita. Quando, em seguida, a tecnologia permitiu, Masagão e demais produtores optaram pela versão em DVD o que possibilitou a entrega do material ao público com um MENU de quadros que podem ser acessados numa ordem individualmente estabelecida, personalizada. Ou seja, rompe-se com a narrativa com começo, meio e fim até mesmo no zapping do espectador. 
presente. Escovar a história à contrapelo é libertar os mortos, aprisionados nas ruínas amontoadas pelo que chamamos de progresso, é cumprir a tarefa geracional que nos cabe, reconhecendo nominalmente nossos mortos e garantindo-lhes que não foram abatidos em vão. Conhecer a história é despertar o presente da sonolência causada pela "obtusa fé no progresso, $[\ldots]$, pela excessiva confiança dos políticos no apoio das massas, e pela subordinação servil a um aparelho incontrolável" (Benjamin, 1994, p. 227).

A velocidade e a grandeza do progresso do início do século $X X$ aparecem, em especial, no fragmento "Paris à noite". O denso movimento urbano e o tamanho monumental das vias públicas mostrados em imagens panorâmicas são ilustrativos da fantasmagoria moderna que fez da velocidade a metáfora do progresso e, desse último, a promessa de uma distribuição mais justa dos benefícios da modernidade tempo em que todos, em igualdade de direitos, teriam acesso à liberdade, de maneira fraterna. Paris, referência ocidental, dos ideais revolucionários, dos tempos democráticos, da ilustração, enfim "lugar da civilização". Aqui o movimento humano é apresentado em confluência com as engrenagens das máquinas, transformando-se na velocidade delas - à sua imagem e semelhança - o corpo que sai do balé, organicidade do corpo, e assume o ritmo/velocidade da máquina, da eletricidade.

Nas palavras de Benjamin (apud KOTHE, 1991, p. 161),

A concepção de progresso do gênero humano ao longo da história é algo inseparável da concepção de que esta transcorra num tempo homogêneo e vazio. A crítica à concepção desse processo precisa constituir o fundamento da crítica à própria concepção de progresso.

A esta noção de progresso Nós que aqui estamos... faz crítica implacável, na medida em que inseparável da concepção de história expõe, esta última, em sua inquestionável heterogeneidade, porosidade e deformidade. Misturam-se ditadores, pensadores, anônimos numa ciranda sem vencedores. Ao contrário, todos parecem derrotados pelo peso da história por todos contruida/destruída. Não há heróis, "pois o herói moderno não é um herói: apenas representa o papel de herói. A modernidade heróica mostra ser uma tragédia em que o papel do herói está vago" (BENJAMIN apud KOTHE, 1991, p. 119). No fragmento Eu, Tu, Ele aparecem os líderes políticos e intelectuais do século, uns ditando teorias, articulando conceitos avisando que "os homens não são senhores dentro de sua própria casa", com Freud por exemplo. Assertiva que muitos dos outros que ali aparecem desconsideraram, levando às últimas conseqüências o mito do homem autotélico, impondo ao mundo seus ideais eugênicos, excludentes, fazendo de suas pequenas histórias grandes eventos.

Nada e ninguém escapam, todos participam como autores ou cúmplices dos horrores vividos naquele século. As vanguardas aparecem em quadros, performances e fotografias como numa provocativa e desdenhosa estampa daquilo que Sevcenko já afirmara lendo o anjo da história em Walter Benjamin. Diz Sevcenko (apud OLIVEIRA et al, 1995 , p. 48), 
Ele [Walter Benjamin] e Klee se sentiram traídos, mas muitos intelectuais e artistas envolvidos na vanguarda dispuseram-se de boa vontade a colaborar com os novos poderes, na Europa e nos Estados Unidos, sobretudo depois da guerra. Revelação final, portanto: a vanguarda em si não foi traída, ela mantinha no seu íntimo uma correspondência com as 'forças do progresso'.

Nós que aqui estamos... não simula o passado em imagens, não enfraquece a realidade trágica do século XX numa representação cinematográfica para o consumo imediato e efêmero. Coloca, por outra face, o cinema como arte política - uma forma estética comprometida com um espaço/tempo - que reverbera, finge que se afasta com o acender das luzes e volta a perturbar o espectador. Como afirma Susan BuckMorss (2001, p. 24-25)a arte política aparece,

\begin{abstract}
Como uma forma de cognição através dos sentidos corporais, a experiência estética tem o poder de desmerecer os significados culturais oficiais, e informar nosso lado corpóreo crítico, o lado que toma sua posição ao lado do sofrimento e da dor humanos onde quer que estes ocorram, apoiando as possibilidades de transformação social desaprovadas pelas estruturas presentes. (grifo da autora)
\end{abstract}

No fragmento A proximidade de Deus, o filme-ensaio "toma sua posição" e reconhece a "dor humana" mostrando a ambigüidade do gesto de todas as religiões, que enunciando elevadas intenções separaram, sacrificaram e desprotegeram seus crentes. A ironia é a arma mais eficaz usada no trecho como modo de revelação das injustiças, que crava em nós, como faca afiada, o olhar da criança que "de uma esquina qualquer está à espera de Deus".

Fragmento e totalidade compõem a dialética moderna dos processos políticos sociais, a partir das experiências midiáticas. Se, de um lado, a idéia de unidade fornece a falsificação da ideologia progressista dos últimos 200 anos, desde as revoluções européias - francesa e industrial inglesa -, na construção do mito do progresso como inerente ao desenvolvimento da espécie humana; de outro lado, a fragmentação, como efeito dos processos de industrialização e modernização tecnológica, instala-se com mais vigor durante o século $\mathrm{XX}$, como a contraparte do idealizado, exatamente pondo em questão a história da modernidade e, muitas vezes, estampando seus fracassos sociais.

O diferencial tecnológico oferecido pelos meios de comunicação, disponíveis especialmente naquele século, renova as formas autoritárias e absolutistas de governar de épocas anteriores, uma vez que potencializa o arregimentar das massas. Walter Benjamin (1994, p. 194), pensando no processo de organização das massas no fascismo, fala do cinema nesse potencial propagandista dos interesses do Estado:

Deve-se observar aqui, especialmente se pensarmos nas atualidades cinematográficas, cuja significação propagandística não pode ser superestimada, que a reprodução em massas corresponde de perto à reprodução das massas. Nos grandes desfiles, nos comícios gigantescos, nos espetáculos esportivos e guerreiros, todos captados pelos aparelhos de filmagem e gravação, a massa vê o seu próprio rosto. (grifos do autor). 
Dessa forma, para fissurar a imagem única, aquela colaboracionista do totalitarismo, o fragmento pode ser a noção técnica mecânica de corte no sentido de isolar uma parte. Interromper o fluxo rentável da máquina propagandista a partir daquilo que ela mesma institui como ação produtiva industrial, que é o corte. Numa antítese que é própria do fazer cinema, a lâmina que introduz o descontínuo na percepção humana, incapacitando o olhar que faz ligações entre as experiências políticas ao longo da história, deve ser a mesma lâmina usada para fazer a disjuntiva da imagem idealizada pelos regimes políticos totalitários. ${ }^{3}$

Interpretando a visão a contrapelo da história, de Walter Benjamin, Sérgio Paulo Rouanet (1981, p. 20-1) distingue a tarefa revolucionária da crítica em operar a lâmina:

\begin{abstract}
A atitude revolucionária fundamental consiste em tomar o partido dos vencidos, e do ponto de vista dos vencidos a história é uma sucessão de desastres, sem nenhuma legalidade imanente, sem nenhum telos, sem nenhuma ordem. Cada momento revolucionário impõe a tarefa de transgredir a história dos vencedores, de desarticulá-la, de imobilizar seu fluxo, de extrair do seu continuum os passados cativos, de despertar de suas sepulturas os mortos, que dependem de cada presente para que a vitória dos opressores não seja definitiva.
\end{abstract}

O fragmento, porque cinde o fluxo contínuo da imagem totalitária, torna visível a crise omitida na imagem. Destacado o fragmento, ele exige o jogo de significados que é, simultaneamente, o de esvaziá-lo do sentido atribuído pelo contínuo da completude da imagem e atribuir-lhe outro significado, pela particularidade de ser fragmento. Ou seja, percebendo o descontínuo é mais fácil atribuir outros significados ao contexto que não aqueles forjados pela ideologia totalitária.

Num quadro, que pode ser o último ou o primeiro, contrariando o cinza e preto que costumam acompanhar a morte, as imagens em preto e branco que predominam em Nós que aqui estamos... vão dando lugar ao colorido em imagens do cemitério, encaminhando-nos por entre túmulos até a saída do lugar. Neste momento, percebese que a narrativa vinha de dentro para fora do cemitério. Dando voz aos mortos da história, o filme-ensaio assevera o inevitável, tanto a morte quanto a continuidade da história.

Um cemitério que não ostenta a matéria política, apenas guarda os corpos e assinala o lugar no qual todos estão sendo esperados, pois se a cultura como construção humana nos distingue, a natureza em sua infernal repetição nos iguala como memória. O cemitério, o espaço subúrbio da cidade-história, tomado pelo frontispício como alegoria ${ }^{4}$, aparece como uma dobra que, num sentido, represente a inseparável tensão entre o dentro e o fora do poder legitimado como centro, que tenta se apossar da história para contar a falsificação das glórias dos grandes eventos.

\footnotetext{
${ }^{3}$ É de Walter Benjamin (1994, p. 104) que vem o valor crítico do corte maquínico, que assumido como técnica moderna do olhar, permite que qualquer objeto seja analisado sem a ilusão da idéia antiga de permanência da "grande obra": "Em última instância, os métodos de reprodução mecânica constituem uma técnica de miniaturização e ajudam o homem a assegurar sobre as obras um grau de domínio sem o qual elas não mais poderiam ser utilizadas".

${ }^{4}$ Para Benjamin (apud BUCK-MORSS, 2002, p. 241), "(...), a alegoria se refere ao estranhamento da aparência ilusória que procede de toda a 'ordem dada', seja da arte ou da vida, da ordem transfigurada totalidade ou do orgânico, (...)".
} 
Uma construção da história que olha para trás, em lugar de olhar para frente, para a destruição da natureza material como ela de fato aconteceu, estabelece contraste dialético com o mito futurista do progresso histórico (que só pode ser sustentado com o esquecimento do que aconteceu). (BUCK-MORSS, 2002, p. 128). (grifos da autora)

Nós que aqui estamos... é arte autoconsciente, que pela estética do fragmento, reafirma o que não se pode esquecer.

\section{Referências}

ADORNO, Theodor. Notas de Literatura I. Trad. Jorge de Almeida. São Paulo: Editora 34, Coedição: Duas Cidades, 2003.

BENJAMIN, Walter. Sobre o conceito da história. In. Obras escolhidas. 7. ed. Magia e Técnica, Arte e Política. Ensaios sobre literatura e história. v.1 São Paulo: Brasiliense, 1994.

BUCK-MORSS, Susan. What is political art? [O que é arte política]. Trad. Ana Luiza Andrade. In: ANDRADE, Ana Luiza (Org.). Dossiê Leituras benjaminianas. Chapecó, SC: Argos, 2001.

. Dialética do olhar. Walter Benjamin e o Projeto das Passagens. Trad. Ana

Luiza Andrade. Belo Horizonte, MG: UFMG, Chapecó, SC: Argos, 2002

CHAUÍ, Marilena. Cidadania cultural e o direito à cultura. São Paulo: Fundação Perseu Abramo, 2006.

KOTHE, Flávio R. (Org. e Trad.). Walter Benjamin. São Paulo: Ática, 1991.

MACHADO, Arlindo. O filme-ensaio. Revista Concinnitas. Ano 4, v.5, dez./2003.

Disponível em: HTTP://www.concinnitas.uerj.br/resumos5/machado.pdf Acessado em: 05 de maio de 2011.

NÓS QUE AQUI ESTAMOS POR VÓS ESPERAMOS. Diretor Marcelo Masagão. Rio de Janeiro: Rio Filme, 1998.

SEVCENKO, Nicolau. O enigma do pós-moderno. In: OLIVEIRA, Roberto Cardoso et al. Pós-modernidade. 5. ed. Campinas, SP: UNICAMP, 1995.

A corrida para o século XXI. No loop da montanha-russa. São Paulo: Cia das Letras, 2001. 


\section{Title}

The Dead of the Twentieth Century: The Past in Fragments and Little Stories

\section{Abstract}

Consistent with the political sense of those narratives on history, the present paper approximates Marcelo Masagão and Walter Benjamin for an interpretive reading of the 'essay-film' Nós que aqui estamos por vós esperamos (1998). Far from trying to introduce subtitles in the narrative of images by Masagão with the notions by Benjamin, the reflection here advanced restates the task of revolving the debris of the past in order to think on the present. Considered one of the most instigating Brazilian films for the investigation of the political role of the public as citizens, this 'essay-film' is discussed under the perspective of the artistic experience as a form of knowledge.

\section{Keywords}

Essay-film. Cultural history. Marcelo Masagão. Walter Benjamin.

Recebido em 13.05.2011. Aprovado em 11.07.2011. 